\title{
Diphyllobothrium latum
}

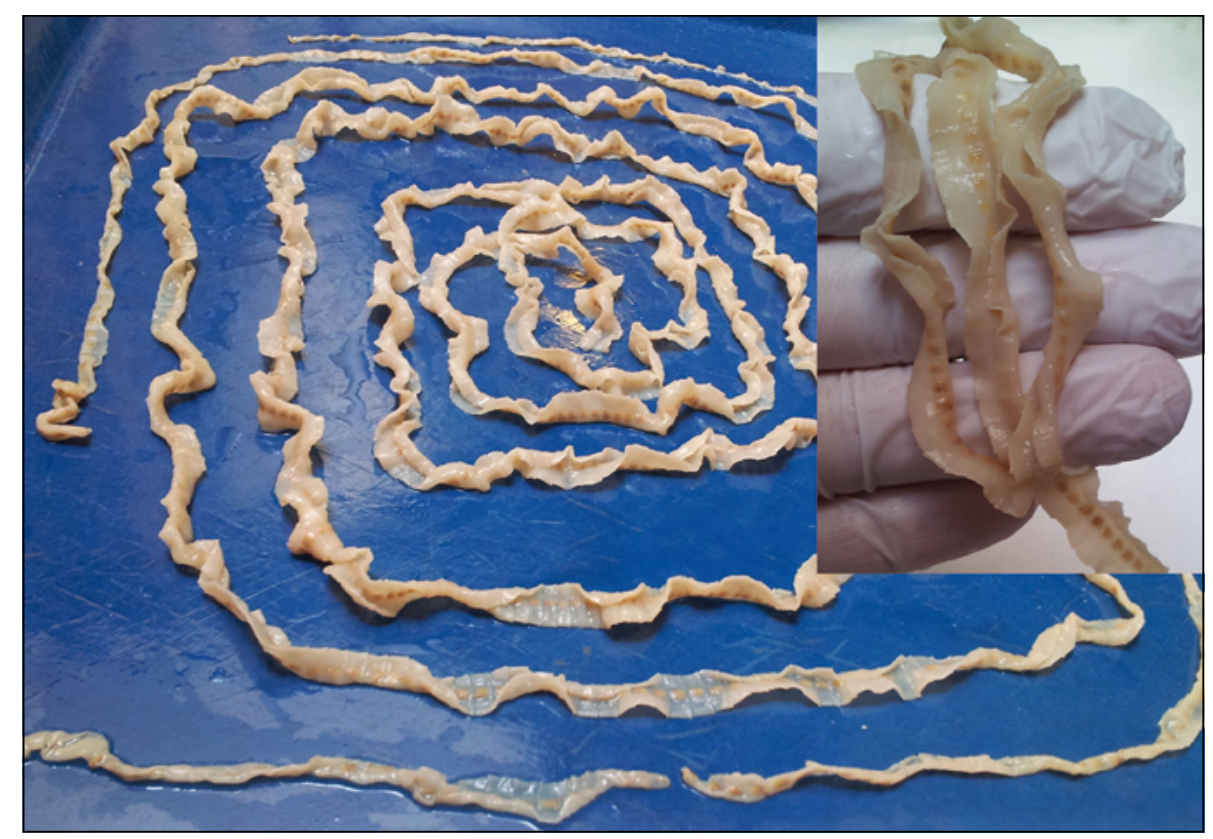

Figura 1. Estróbilo incompleto de Diphyllobothrium latum que mide $455 \mathrm{~cm}$, con más de 1.000 proglótidas, sin escólex, que fue expulsado en forma espontánea por un paciente que se infectó tras comer ceviche de trucha pescada en la Región de Los Lagos.

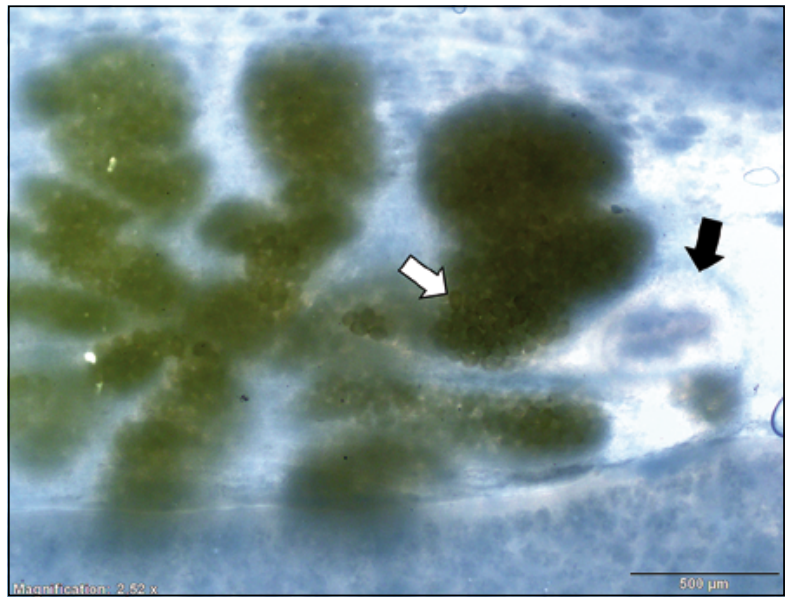

Figura 2. Proglótida de Diphyllobothrium latum bajo microscopía óptica: útero en forma de roseta conteniendo huevos (flecha blanca) y atrio genital central (flecha negra).

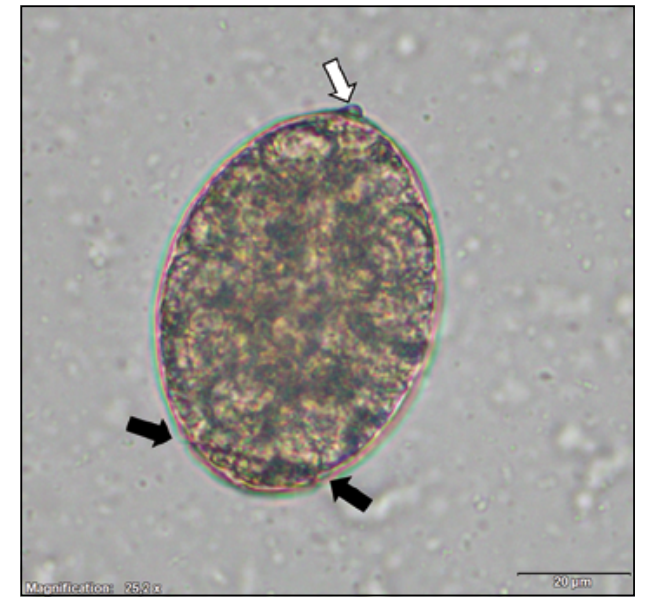

Figura 3. Huevo de Diphyllobothrium latum con opérculo (flechas negras) y botón polar (flecha blanca). En su interior células vitelógenas que rodean el cigoto. 


\section{Diphyllobothrium latum}

Diphyllobothrium latum es un cestodo pseudofilideo que fue introducido en Chile por la llegada de inmigrantes europeos al sur del país. Actualmente es endémico de las zonas lacustres, existiendo en nuestro país dos especies más del género: $D$. dendriticum (de menor tamaño) también en agua dulce y $D$. pacificum que posee un ciclo marino.

El ciclo de vida de D. latum es complejo y requiere dos hospederos intermediarios. Primero, un crustáceo copépodo de agua dulce ingiere el coracidio (estadio larvario inicial). En este crustáceo, la larva alcanza su forma de procercoide. En una segunda etapa, los peces planctófagos que ingieren estos crustáceos desarrollan, en sus vísceras y tejidos, el siguiente estado larvario de plerocercoide. Peces depredadores de mayor tamaño se comportan como hospederos paraténicos, al concentrar en sus tejidos los plerocercoides presentes en los peces de su dieta, lo que facilita la transmisión a los hospederos definitivos (mamíferos ictiófagos) de este parásito. En humanos, el helminto adulto puede vivir hasta 20 años en el intestino delgado. Se adhiere a la mucosa a través de un escólex en forma de espátula, de 2-3 mm, que posee dos botrios (surcos longitudinales). El estróbilo, compuesto por 2.000 a 5.000 proglótidas hermafroditas que son más anchas que largas (10-12 x 2-4 mm), puede crecer hasta un centímetro por hora y llegar a medir hasta 20 metros, característica que convierte a esta especie en el parásito intestinal humano de mayor longitud. El período de prepatencia es de 2-8 semanas, tras el cual los pacientes comienzan a eliminar millones de huevos cada día, de tamaño promedio de 65 por $45 \mu \mathrm{m}$. Estos huevos, con opérculo en uno de sus extremos y un botón polar en el opuesto, una vez que alcanzan el agua dulce pueden permanecer viables por meses o años, dependiendo de temperatura y exposición solar adecuadas para la eclosión del coracidio ciliado. El diagnóstico se basa en la demostración de los huevos o las proglótidas eliminados en las deposiciones de un paciente.

\section{Referencias bibliográficas}

1.- Torres P. Difilobotriasis. Apt W, Editor. Parasitología Humana, 1ª ed. México D.F.: McGraw-Hill; 2013, p. 202-13.

2.- Scholz T, García H H, Kuchta R, Wicht B. Update on the human broad tapeworm (genus Diphyllobothrium), including clinical relevance. Clin Microbiol Rev 2009; 22: 146-60.

3.- Mercado R, Yamasaki H, Kato M, Muñoz V, Sagua H, Torres P, et al. Molecular identification of the Diphyllobothrium species causing diphyllobothriasis in Chilean patients. Parasitol Res 2010; 106: 995-1000.

Reinaldo Rosas y Thomas Weitzel Laboratorio Clínico, Clínica Alemana de Santiago, Facultad de Medicina Clinica Alemana/Universidad del Desarrollo. 